\title{
PREDICTING EXPLOSION AND BLAST EFFECTS: A MULTI-SCALE EXPERIMENTAL APPROACH
}

\author{
SOPHIE TRÉLAT ${ }^{1} \&$ MICHEL-OLIVIER STURTZER ${ }^{2}$ \\ ${ }^{1}$ IRSN, Institut de Radioprotection et de Sûreté Nucléaire, France. \\ ${ }^{2}$ ISL, French German Research Institute of Saint Louis, France.
}

\begin{abstract}
Critical infrastructures protection evaluation when exposed to terroristic or accidental blast wave propagation represents a core topic of research for the French public institute IRSN and the French-German military research institute ISL. The Institute for Radiological Protection and Nuclear Safety (IRSN) and the French-German Research Institute of Saint Louis (ISL) actively cooperate on the evaluation of pressure effects generated by blast wave propagating in hemispherical geometry. During the past few years, IRSN developed a significant experience on hemispherical blast effect assessment using $42 \mathrm{~g}$ reference Hexomax ${ }^{\circledR}$ charges detonated in contact to a planar surface equipped with different types of pressure sensors (piezo-electric and piezo-resistive). Based on this experience, ISL developed an outdoor blast-pad located at its own explosive range: 400g TNT equivalent charges are detonated in a factor 2 up-scaled version of IRSN test configuration. Similar sensors are flush-mounted inside a metallic rail integrated below the concrete pad surface. The objective of this joint work is to improve the knowledge on scaling laws for small plastic explosive charges (Semtex, C4 and Hexomax ${ }^{\circledR}$ ) and their corresponding TNT equivalencies. To achieve this goal, TNT charges were produced at ISL in order to provide a direct, realistic and reproducible reference at the corresponding scale. In addition, the influence of the pressure gauge technology on the blast characteristics was studied and a methodology was developed to minimize this influence and provide guidelines for results comparison between research institutes. Finally, the pressure profiles were also analysed taking into account the fine structure of the shock interacting with the blast pad surface using high-speed imaging.
\end{abstract}

Keywords: Blast wave, critical infrastructure protection, high explosives, scaling laws, TNT equivalent.

\section{INTRODUCTION}

The Institute for Radiological Protection and Nuclear Safety (IRSN) is a French public institute with industrial and commercial activities, placed under the joint authorities of the Ministries of Defence, Environment, Industry, Research, and Health. IRSN is entrusted, among others, to assess and conduct researches in the area of the protection of nuclear facilities and transport of radioactive and fissile materials against accidental and malicious acts. In this context, IRSN establishes projects and studies to improve its knowledge of blast characteristics and weapons effects.

The French-German Research Institute of Saint Louis (ISL) is a bi-national research institute established by the Federal Republic of Germany and the French Republic on the basis of a treaty signed in 1958. The core mission of ISL is: "Research, scientific studies and basic predevelopment in the field of defence and security". Among other tasks, ISL focuses on the physical protection of personnel and assets against the effects of various explosive charges. To improve general survivability, fundamental studies on blast wave propagation and target interaction are continuously being conducted at ISL.

In 2006, IRSN designed and built an experimental set-up to achieve non-destructive shock wave propagation studies on a small scale $[1,2]$. This set-up is composed of a modular table, sensors and targets able to perform the detonation of solid explosives up to $64 \mathrm{~g}$ of TNT equivalent, representing an alternative to the gas mixture detonation propagation configuration for small scale tests [3, 4]. In this document, we focus on the characterization of blast generated by different types of plastic explosives: Hexomax ${ }^{\circledR}$, C-4 and Semtex. Pressure profiles were 
recorded in free-field at two different scales for Hexomax ${ }^{\circledR}$ and at single scale for TNT, C-4 and Semtex. Results are compared to TNT data obtained in the same configuration (to improve precision in comparison with large scale test literature results [5]). Finally, we investigate the effect of signal post-processing and the influence of pressure gauge technology on the resulting TNT equivalencies for one of the multiple possible blast characteristics [6, 7]: peak overpressure.

\section{EXPERIMENTAL CONFIGURATIONS}

The IRSN blast table has been principally designed to study shock waves reflection phenomena and interaction with different non-deformable structures. It measures $1.6 \times 2.4$ meters and features an array of mounting holes that facilitates the placement of modular $0.4 \times 0.4 \times 0.05 \mathrm{~m}$ wooden plates, and pressure transducers (see Fig. 1 left). For this campaign, different types of pressure transducers (piezo-electric and piezo-resistive) separated by $133 \mathrm{~mm}$ are mounted on an elastic support and their signals were recorded at $500 \mathrm{kHz}$ by a Nicolet Genesis data acquisition system. Explosive charges are installed and ignited on a dedicated reinforced steel table plate to generate a hemispherical blast wave using a Davey-Bickford SA 4201A detonator.

ISL developed a dedicated outdoor blast pad (Fig. 1 right): explosive charges are detonated in a factor 2 up-scaled version of IRSN test configuration. For this campaign, different types of pressure transducers (piezo-electric and piezo-resistive) are mounted on a polypropylene support inserted in one of the integrated rail ports, each separated by $266 \mathrm{~mm}$. All data were recorded using a Transcom system running at $2 \mathrm{MHz}$. Explosive charges are installed and ignited by a RP83 detonator on a dedicated reinforced steel ground plate to generate a hemispherical blast wave.

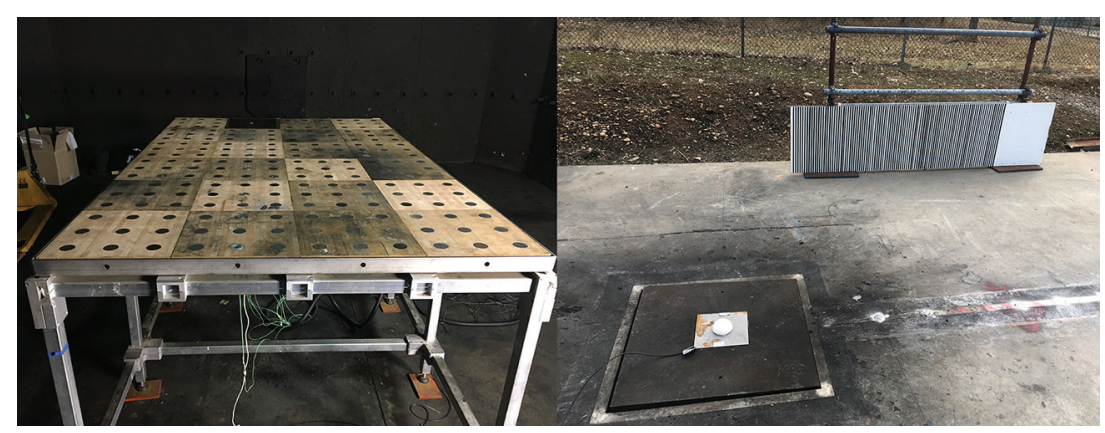

Figure 1: IRSN blast table and ISL blast pad.

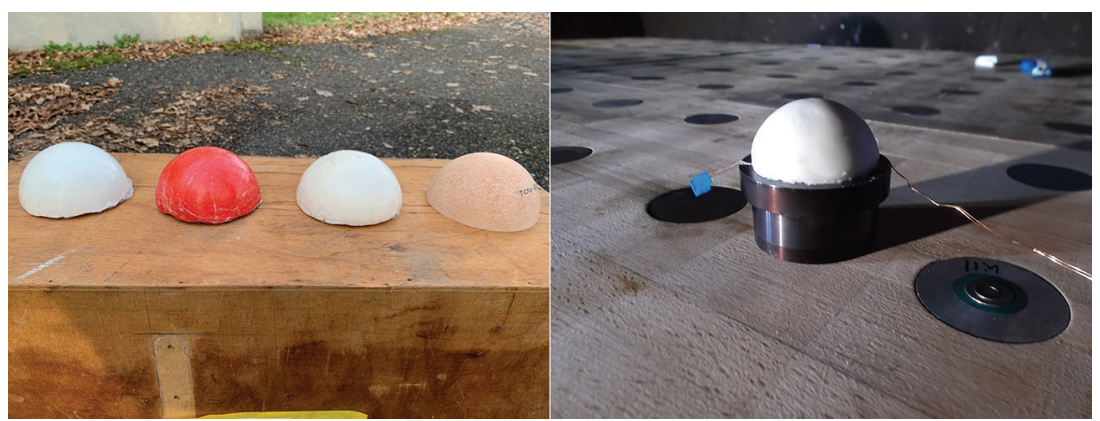

Figure 2: Hexomax ${ }^{\circledR}$, Semtex, C-4, TNT at ISL range (left), Hexomax ${ }^{\circledR}$ at IRSN (right). 
Table 1: Explosive tests metrology specifications.

\section{Test reference number}

ISL configuration

IRSN configuration

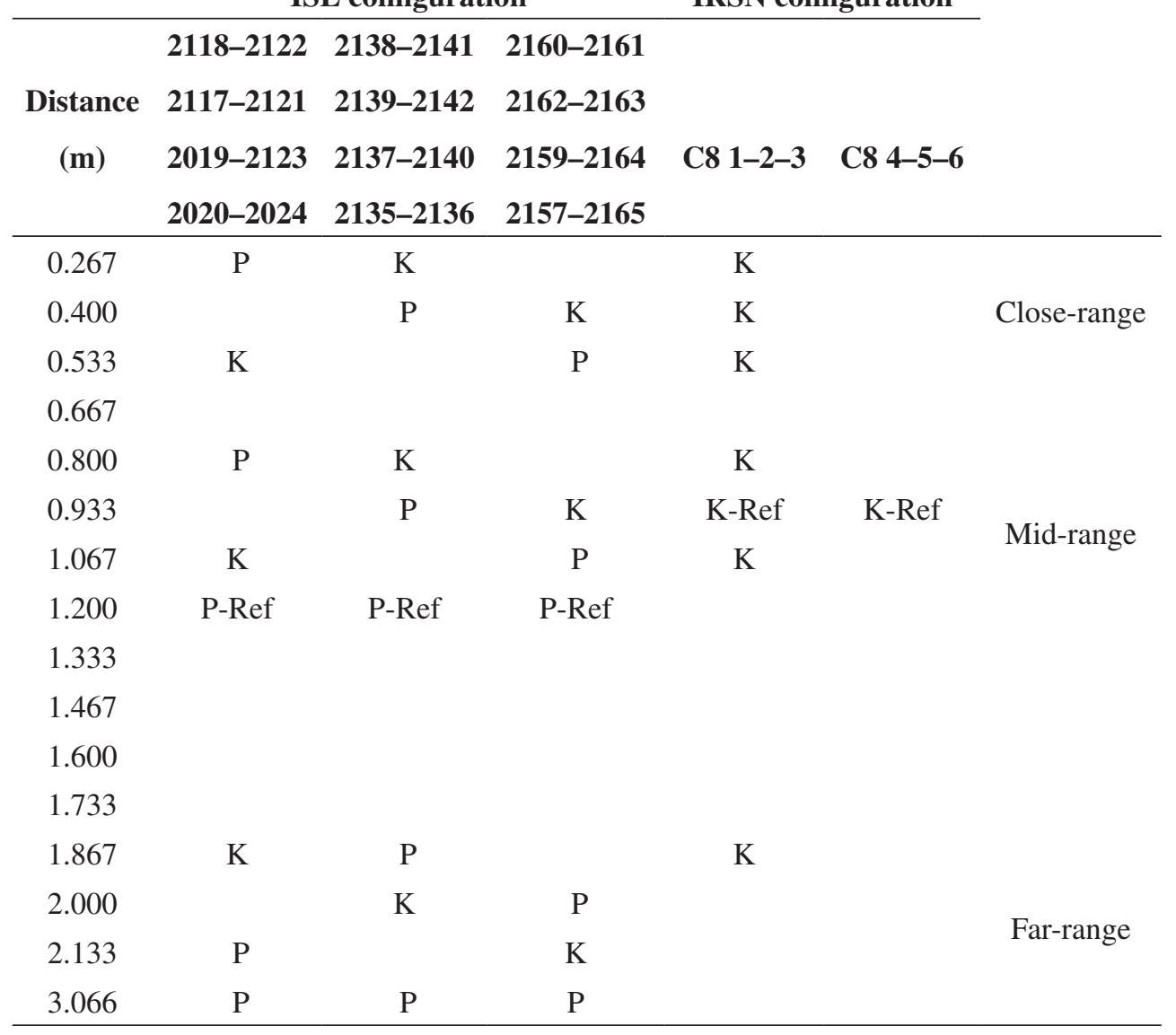

The authors would like to draw the reader's attention to the fact that all distances presented in the rest of this document correspond to IRSN scale. ISL distances and times have all been downscaled for direct comparison. Table 1 presents the position of all sensors for both test series (reduced distances $\mathrm{Z}$ ranging between 0.57 and $4.6 \mathrm{~m} . \mathrm{kg}^{1 / 3}$ for a spherical charge). We arbitrarily divided our $\mathrm{Z}$ range in close, mid and far range, at the study scale, for interpretation purposes. The different sensors used are: Kulite XT190 or HKS375 (K), PCB M102A, M102A6 or 113B28 (P), Kistler 603B (K-Ref) and PCB 113B28 (P-Ref).

Interscale comparison tests were conducted by detonating hemispherical Hexomax ${ }^{\circledR}$ charges described in Table 2 with masses, respectively, 41.6 and $333 \mathrm{~g}$ at IRSN and ISL, leading to 50 and $400 \mathrm{~g}$ TNT equivalency (in overpressure), based on manufacturer specifications. Figure 2 shows the four hemispherical explosives charges tested at ISL range (Hexomax ${ }^{\circledR}$, Semtex, C-4, and TNT at ISL range) and the hemispherical Hexomax ${ }^{\circledR}$ charge at IRSN range. 
Table 2: Explosive charges characteristics.

\begin{tabular}{lccccc}
\hline Configuration & $\begin{array}{c}\text { IRSN } \\
\text { Hexomax }^{\circledR}\end{array}$ & $\begin{array}{c}\text { ISL } \\
\text { Hexomax }^{\circledR}\end{array}$ & ISL TNT & ISL C-4 & ISL Semtex \\
\hline Mass (g) & 41.6 & 333 & 336 & 295 & 295 \\
Diameter (mm) & 46.6 & 94 & 97 & 93 & 94 \\
Density (g/cm $\left.{ }^{3}\right)$ & 1.58 & 1.54 & 1.63 & 1.59 & 1.55 \\
TNT equivalent & 1.2 & 1.2 & 1 & 1.35 & 1.35 \\
in overpressure & & & & & \\
Test reference \# & $1,2,3,4,5,6$ & 2118,2122, & 2117,2121, & 2119,2123, & 2120,2124, \\
& & 2138,2141, & 2139,2142, & 2137,2140, & 2135,2136, \\
& & 2160,2061 & 2162,2163 & 2159,2164 & 2157,2165 \\
\hline
\end{tabular}

\section{REPRODUCIBILITY}

IRSN reproducibility is assessed using K-Ref sensor (Kistler 603B) present for each test at 0.933 $\mathrm{m}$. This position fits into the mid-range distances to the charge. For this study, we only analyse the positive phase of the leading wave representing one standard technique for TNT equivalency determination presented in literature [8,9]. We also calculated mean relative deviation (in \%) (eqn (1)) for measured peak overpressures. Resulting deviation in overpressure did not exceed 5\%. Even secondary shock proved to be repeatable, except for a slight profile difference for test 5 .

$$
\text { Deviation }=\frac{1}{n \times \operatorname{Average}\left(X_{1}, X_{2} . . X_{n}\right)} \sum_{i=1}^{n}\left|X_{i}-\operatorname{Average}\left(X_{1}, X_{2} . . X_{n}\right)\right|
$$

ISL reproducibility is assessed using P-Ref sensor (PCB 113B28) present for each test at $1.2 \mathrm{~m}$. This position also fits into the mid-range distances to the charge. Deviation for peak overpressure did not exceed $5 \%$ and $8 \%$, respectively, for TNT and Hexomax ${ }^{\circledR}$. As expected, reproducibility of secondary shock profile was lower than for the small IRSN charges. Arrival times and maximum overpressure amplitudes proved to vary between tests.
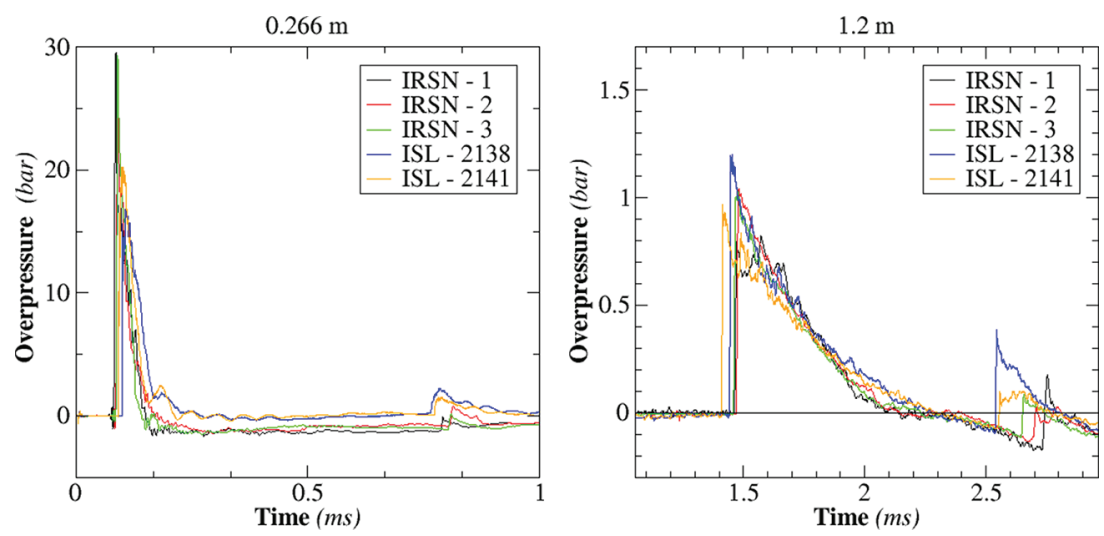

Figure 3: Interscale Hexomax ${ }^{\circledR}$ pressure evolution recorded at 0.266 and $1.2 \mathrm{~m}$ (IRSN scale). 
Figure 3 presents the interscale comparison of Hexomax ${ }^{\circledR}$ pressure profiles recorded at 0.266 , and $1.2 \mathrm{~m}$. In close range, blast characteristics are globally in good agreement despite some differences in peak shape and time of arrival. Pressure decay behind the leading shock is however significantly different between the two series of tests: sensor drift may explain this phenomenon. At mid-range, the blast wave structure becomes more uniform and the pressure profiles more similar for the different tests. Arrival time of the secondary shock remains different for the two scales, certainly due to the non-scalability of fireball reactions [10].

\section{BLAST CHARACTERISTICS DETERMINED BY PIEZORESISTIVE SENSORS}

Based on overpressure versus scaled distance for the $400 \mathrm{~g}\left(\mathrm{M}_{\mathrm{TNT}-\mathrm{ISL}}\right) \mathrm{TNT}$ charges placed on ground (diamonds on Fig. 4), the following experimental correlation (eqn (2)) was determined for scaled distances between 0.5 and $4 \mathrm{~m} / \mathrm{kg}^{1 / 3}$ (dashed line on Fig. 4):

$$
\frac{\Delta P}{P_{0}}=7.9147 \times Z^{-2.045}
$$

Figure 5 represents all peak overpressure measured for Hexomax ${ }^{\circledR}$ charges at IRSN and ISL scales using Kulite piezo-resistive gauges. They are compared to the $50 \mathrm{~g}$ TNT overpressure evolution calculated with Kinney \& Graham equations [8]. Results obtained at both scales are in reasonably good agreement.

Based on eqn (2), each overpressure $\mathrm{P}_{\mathrm{H}}\left(\mathrm{d}_{\mathrm{H}}\right)$ measured at distance $\mathrm{d}_{\mathrm{H}}$ for Hexomax ${ }^{\circledR} 41.6 \mathrm{~g}$ charge provides a corresponding TNT scaled distance:

$$
Z_{e q}=\left(\frac{7.9147}{\frac{\Delta P_{H}}{P_{0}}}\right)^{\frac{1}{2.045}}
$$

Equivalent TNT mass can thus be calculated by:

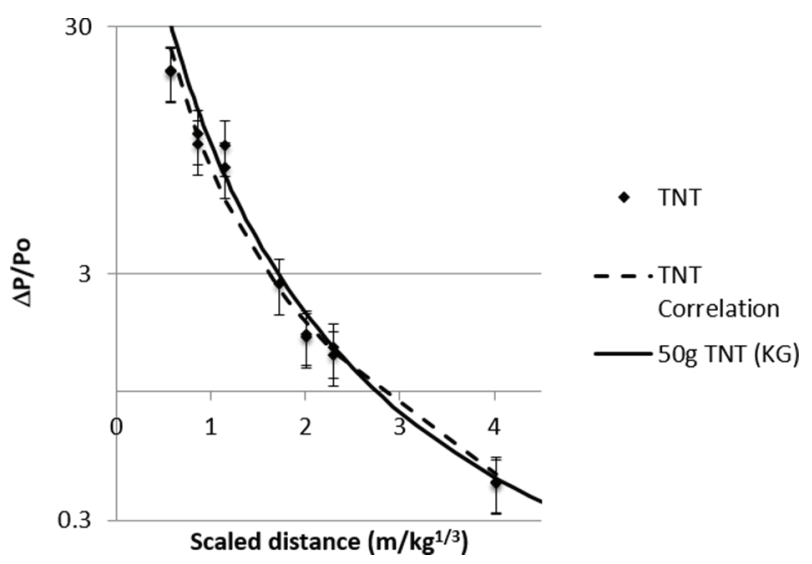

Figure 4: TNT peak overpressure evolution versus scaled distance, resulting correlation and comparison with analytical equation [8] for $50 \mathrm{~g}$ TNT charge. 

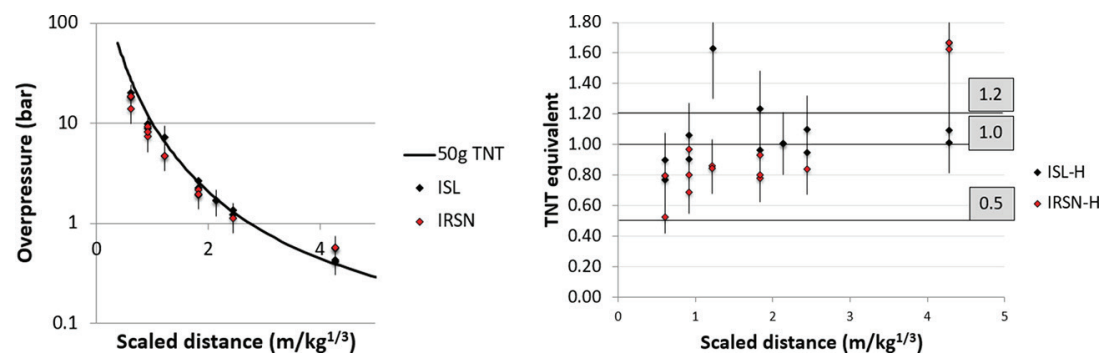

Figure 5: Peak overpressure and TNT equivalency versus scaled distance for Hexomax ${ }^{\circledR}$.

$$
M_{T N T e q}=\left(\frac{d_{H}}{Z_{e q}}\right)^{3}
$$

Calculated TNT equivalency in overpressure versus distance for the two series of Hexomax ${ }^{\circledR}$ tests (IRSN and ISL) is presented on Fig. 5. Its values range from less than 1 in close range to 1.5 in far-range. These values can be compared to the Hexomax ${ }^{\circledR}$ manufacturer's provided 1.2 equivalent. For scaled distance lower than $3 \mathrm{~m} / \mathrm{kg}^{1 / 3}$, IRSN charges seem to generate lower levels of overpressure: absolute dimension of the charge may be responsible for this discrepancy.

ISL reproducibility for C-4 and Semtex was evaluated at $1.2 \mathrm{~m}$ (mid-range) using P-Ref sensor (PCB 113B28). As for Hexomax ${ }^{\circledR}$ (another plastic explosive), global reproducibility is worse than for TNT or Hexomax ${ }^{\circledR}$ at IRSN scale: mean deviation in peak overpressure value is around $15 \%$. Main wave time of arrival, peak overpressure and secondary shock profile significantly vary between tests. Figure 6 represents all peak overpressures measured for C-4 and Semtex charges at ISL scale using K pressure gauges (Kulite). They are compared to the $50 \mathrm{~g}$ TNT overpressure evolution calculated with Kinney \& Graham equations [8].

Calculated TNT equivalency in overpressure versus distance for C-4 and Semtex is presented on Fig. 7. Its values range from less than 1 in close range to 1.5 in far range. These values can be compared to their manufacturer provided 1.35 equivalent.

Two of the main objectives of this study are to validate Hexomax ${ }^{\circledR}$ scalability and to determine experimentally its TNT overpressure equivalency at two different scales. In this series of tests, we often recorded pressure signals that are complex and difficult to process as their profile significantly differs from the classic Friedlander evolution $[4,9]$ notably by presenting multiple peak pressures. As a consequence, we propose a candidate technique named $\mathrm{KG}$ in this document (in reference to [8]) to extract values of peak overpressure from experimental
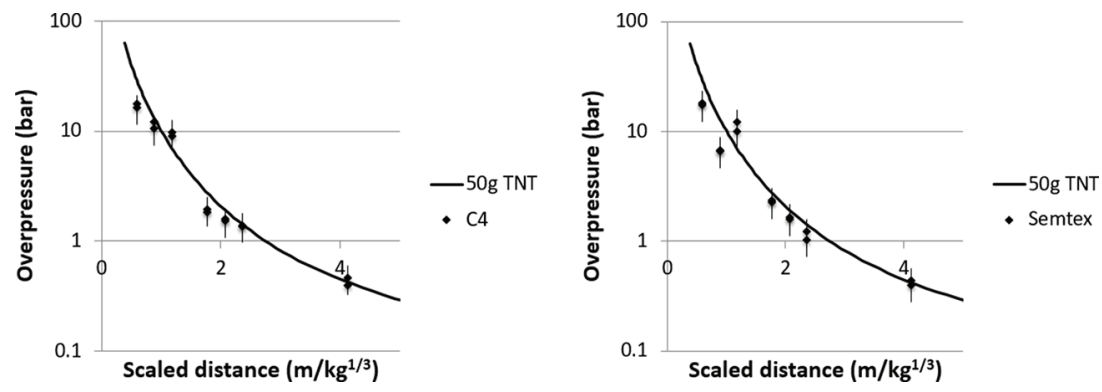

Figure 6: Overpressure versus scaled distance for C-4 and Semtex charges. 

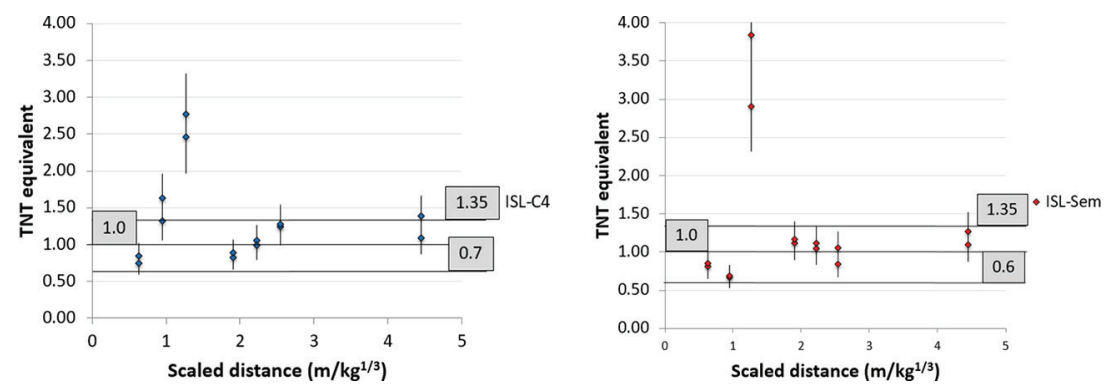

Figure 7: C-4 TNT equivalency versus scaled distance.

signals, especially in close-range. Objectives are to study qualitatively the pressure-time evolutions by sorting them into three main categories and to propose an extension of the classic interpolation method $[8,11]$ to signals including a second peak behind the leading shock.

Among all the overpressure time evolutions recorded for this study, we identified three global types (Fig. 8):

- Type I: regular, single peak overpressure. Time evolution is close to the Friedlander waveform and KG technique described in [8] can directly be applied,

- Type II: double peak. A second peak (higher or lower) is propagating close behind the leading shock. Its arrival time is much shorter than the weaker secondary shock propagating due to the re-expanding rarefaction [12] wave formed at the end of the solid phase detonation phase. The second peak may be generated by a conical shock (as seen on Fig. 18) or by a non-uniform detonation of the explosive charge. In this case, the classic KG technique [8] is applied on the first peak, at the cost of potentially underestimating the total energy release of the explosive charge,

- Type III: multiple peaks (other complex overpressure evolutions). Such signal is processed manually as no criterion was yet proposed to determine the peak overpressure value.

Figure 9 represents the TNT peak overpressures determined directly and by KG technique. It should be noticed that peak overpressures determined with KG technique for TNT are significantly more dispersed than original values measured directly. In addition to the previously determined correlation, a new correlation (eqn (5)) based on processed signals is also represented:

$$
\frac{\Delta P}{P_{0}}=11.508 \times Z^{-2.307}
$$

All pressure signals acquired for Hexomax ${ }^{\circledR}$ charges (IRSN and ISL scales) were processed using the same KG technique. Using eqn (4), we calculated the TNT equivalency for

Type I: regular

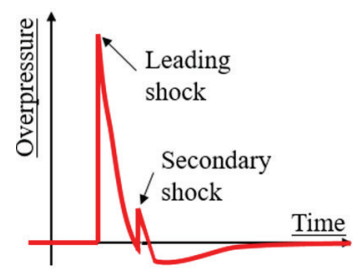

Type II: double

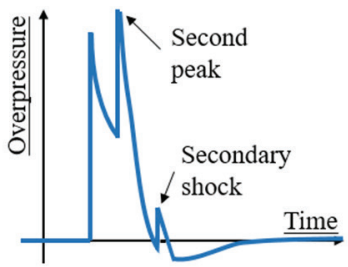

Type III: multiple

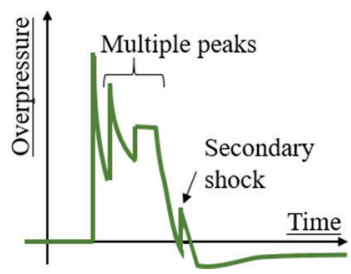

Figure 8: Examples of recorded blast wave pressure signals. 


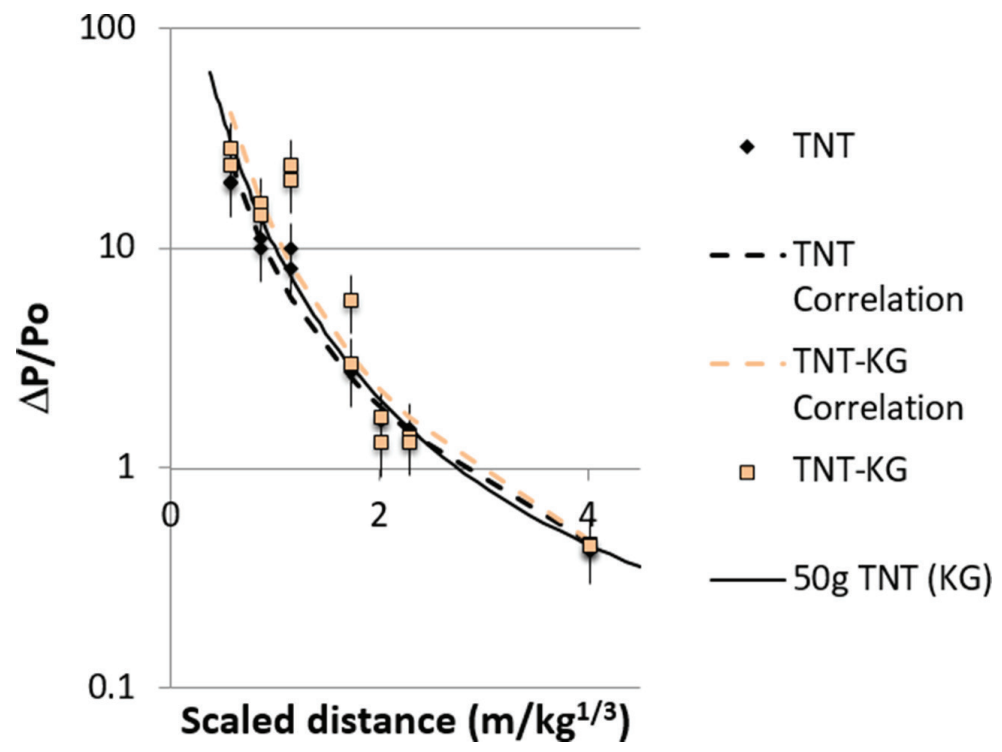

Figure 9: TNT peak overpressure evolution versus scaled distance through direct and KG determination.

each Hexomax ${ }^{\circledR}$ overpressure measurement, using the $\mathrm{KG}$ determined values and the $\mathrm{KG}$ TNT equivalency correlation. The results are compared on Fig. 10: black and red diamonds, respectively, represent ISL and IRSN results, left representing original values, left the KG ones. As for the original results, the KG values are included between 0.5 and 1.3. Despite the additional post-treatment, dispersion of results remains similar. The KG interpolation technique represents a potential candidate for more physical measurement by compensating the pressure sensor shortcomings (rise time, shock sensitivity, etc.).

Pressure signals recorded for C-4 and Semtex tests were processed in the same way as for Hexomax ${ }^{\circledR}$. Their TNT equivalency is presented on Fig. 11. Values are globally progressing on the range of scaled distances, from 0.5 to 1.4 except for some isolated points. However, unlike for Hexomax ${ }^{\circledR}$, results dispersion slightly increases in comparison with directly determined TNT equivalents. Improving the post-processing method could reduce this observed dispersion for C-4 and Semtex. This could also be explained by the pressure profiles observed behind the leading shock for these plastic explosives: these profiles often differed from usual Friedlander profile.
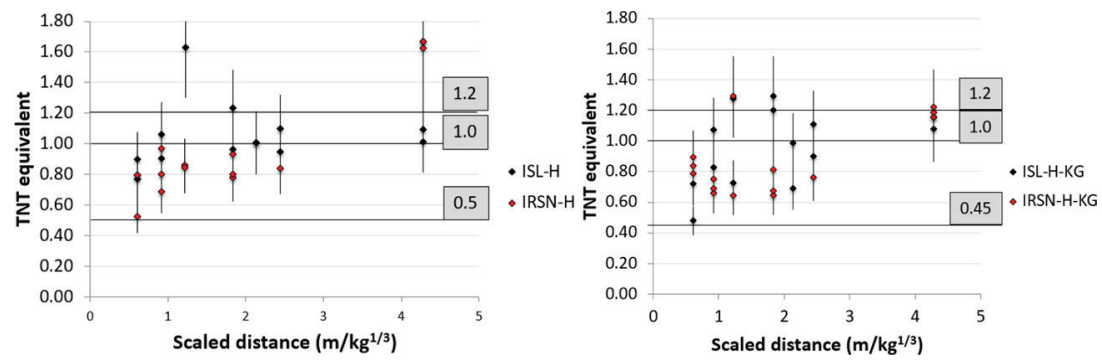

Figure 10: Interscale Hexomax ${ }^{\circledR}$ TNT equivalency versus scaled distance determined by direct (left) and KG (right) method. 

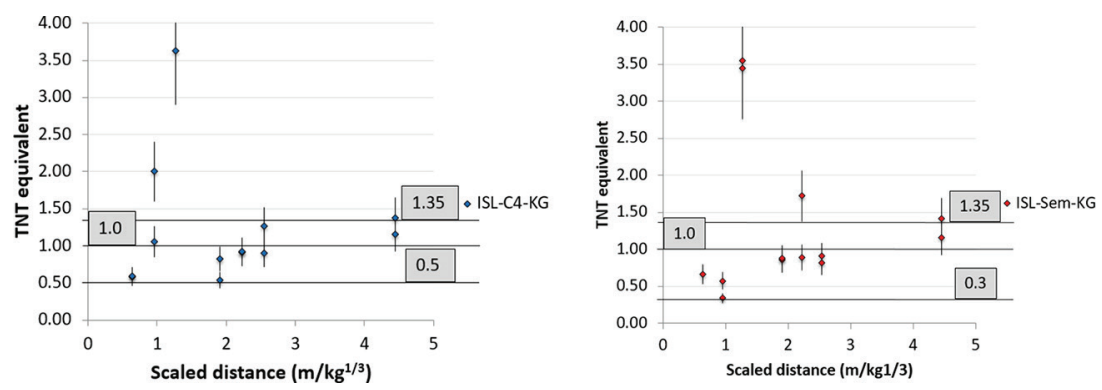

Figure 11: C-4 and Semtex KG TNT equivalency versus scaled distance.

\section{BLAST CHARACTERISTICS DETERMINED BY PIEZORESISTIVE SENSORS} Based on peak overpressure measured by PCB sensor for all TNT tests, a new correlation (eqn (6)) was determined for scaled distances between 0.5 and $7 \mathrm{~m} / \mathrm{kg}^{1 / 3}$, and plotted on Fig. 12, in comparison with the Kulite previously calculated correlation (eqn (2)).

$$
\frac{\Delta P}{P_{0}}=9.654 \times Z^{-2.118}
$$

The PCB TNT reference correlation provides higher peak overpressure than the Kulite correlation: the faster responding piezoelectric sensors generating higher peak overpressure can explain this difference. Due to an additional sensor in far range, the PCB correlation is also calculated on a wider range of scaled distances. The difference between correlations stresses the importance of determining the TNT equivalency with similar sensors used to calculate the reference TNT overpressure versus scaled distance law.

Calculated TNT equivalency in PCB overpressure versus scaled distance for the two series of Hexomax ${ }^{\circledR}$ tests (IRSN and ISL) is presented on Fig. 13, in comparison with the previously determined Kulite TNT equivalency. Below $3 \mathrm{~m} / \mathrm{kg}^{1 / 3}$, the PCB TNT equivalent decreases with the scaled distance, before increasing up to $7 \mathrm{~m} / \mathrm{kg}^{1 / 3}$. Between 2.5 and $5 \mathrm{~m} /$ $\mathrm{kg}^{1 / 3}$, both sets of sensors provide similar TNT equivalency.

Calculated TNT equivalencies in PCB overpressure versus scaled distance for C-4 and Semtex are presented on Fig. 14. As for Hexomax ${ }^{\circledR}$, both TNT equivalents first decrease with

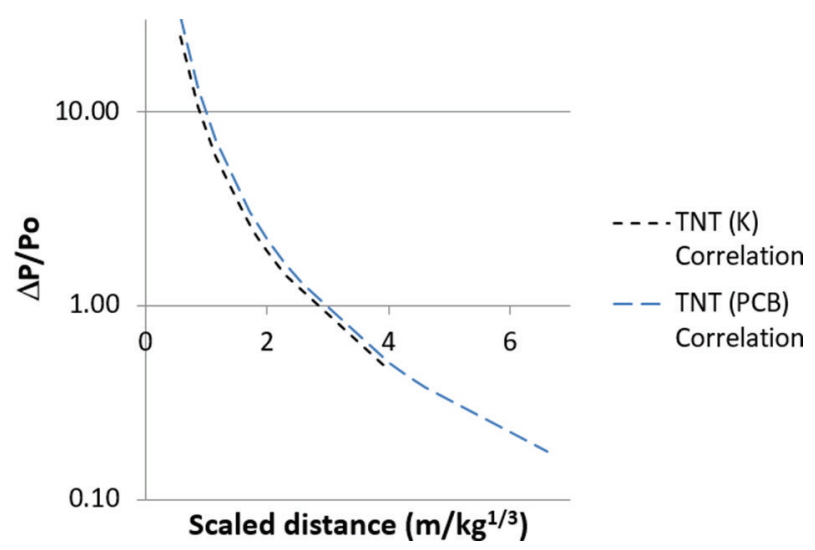

Figure 12: TNT correlations extracted from Kulite and PCB sensor signals. 


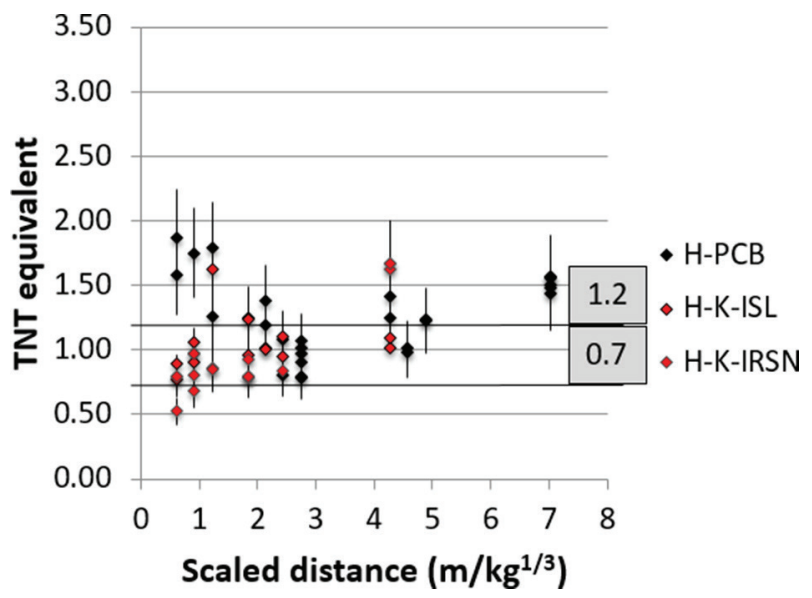

Figure 13: Interscale Hexomax ${ }^{\circledR}$ TNT equivalency versus scaled distance determined with PCB and Kulite sensors.
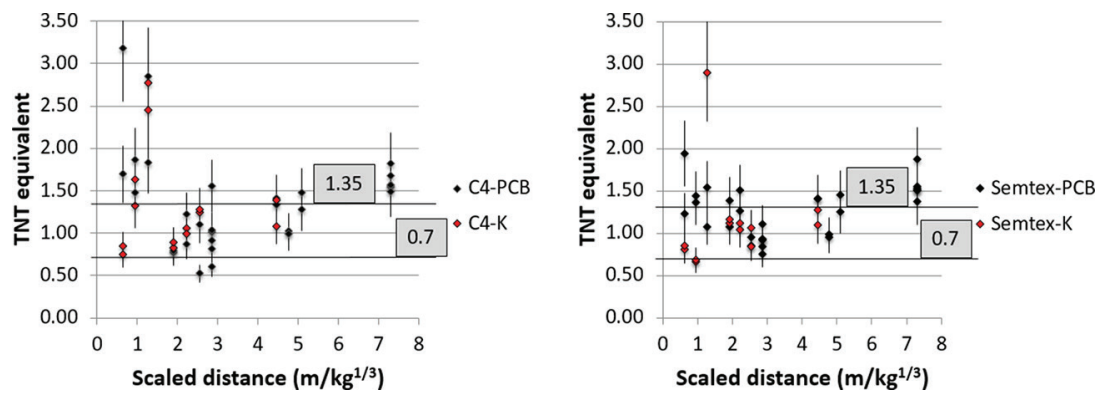

Figure 14: C-4 and Semtex TNT equivalency versus scaled distance determined with PCB and Kulite sensors.

scaled distance (up to $3 \mathrm{~m} / \mathrm{kg}^{1 / 3}$ ) before increasing for further distances. Between 2.5 and 5 $\mathrm{m} / \mathrm{kg}^{1 / 3}$, both sets of sensors provide similar TNT equivalency for both C-4 and Semtex. However, Hexomax ${ }^{\circledR}$ results proved to be less dispersed than C-4 and Semtex. Some excessive peak overpressure recorded at $1.27 \mathrm{~m} / \mathrm{kg}^{1 / 3}$ may be due to a sensor partial failure. As the global trend of TNT equivalency for all three plastic explosives is very similar, a modification of the TNT correlation equation (eqn (6)) in future works may also improve the determined values.

As for Kulite pressure signals (section 4.4), KG method was applied to PCB pressure signals to determine peak overpressure. TNT results lead to a new correlation (eqn (7)) to calculate TNT equivalency (in overpressure) for other explosive compositions.

$$
\frac{\Delta P}{P_{0}}=8.8536 \times Z^{-2.078}
$$

PCB KG correlation evolves slightly below the direct PCB correlation: the usual peak pressure overshoot observed for PCB sensors is partially corrected by the applied KG methodology. 

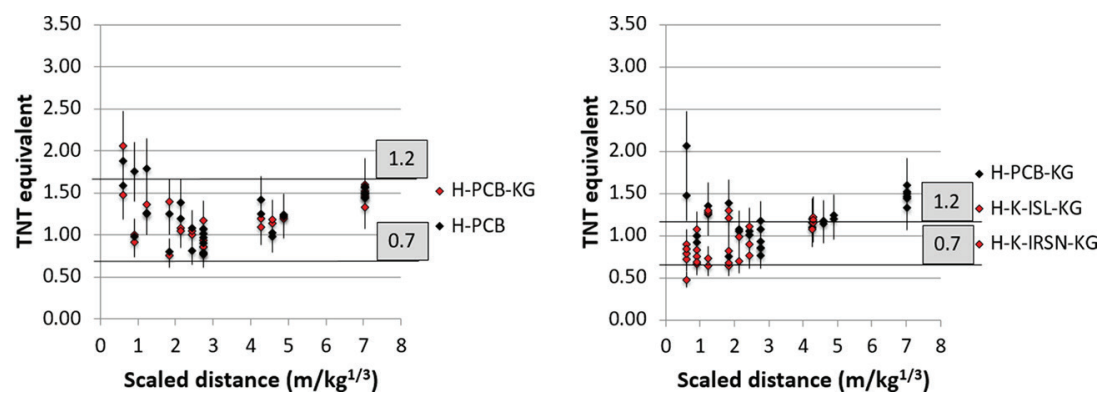

Figure 15: Influence of KG method on PCB sensors (left) and sensor type comparison (right) for Hexomax ${ }^{\circledR}$ TNT equivalency versus scaled distance.

All PCB pressure signals acquired for Hexomax ${ }^{\circledR}$ charges (ISL scales) were processed using the same KG technique. Corresponding TNT equivalency in overpressure versus scaled distance is presented on Fig. 15, in comparison with the directly determined PCB TNT equivalency. Post-processing marginally decreases the dispersion of results on both extremes of the tested scaled distance range. TNT equivalency still decreases from 2 in close range down to approximately 1 at $3 \mathrm{~m} / \mathrm{kg}^{1 / 3}$, before increasing to 1.5 at $7 \mathrm{~m} / \mathrm{kg}^{1 / 3}$. KG calculated TNT equivalency in PCB overpressure versus scaled distance for Hexomax ${ }^{\circledR}$ tests is presented on Fig. 15, in comparison with the previously KG determined Kulite TNT equivalency (IRSN and ISL results). Except for some peak overpressures in close range, there is a general agreement between the different series of values: TNT equivalent globally increases from 0.7 to 1.5 on the studied range of scaled distances.

All PCB pressure signals acquired for $\mathrm{C}-4$ charges were processed using the $\mathrm{KG}$ methodology. Corresponding TNT equivalency in overpressure versus scaled distance is presented on Fig. 16, in comparison with the directly determined PCB TNT equivalency. Post-processing slightly decreases the results dispersion, especially in close range. TNT equivalency globally decreases from 2 in close range down to approximately 0.7 at $3 \mathrm{~m} / \mathrm{kg}^{1 / 3}$, before increasing to 1.5 at $7 \mathrm{~m} / \mathrm{kg}^{1 / 3}$. KG calculated TNT equivalency in PCB overpressure versus scaled distance for $\mathrm{C}-4$ tests is presented on Fig. 16, in comparison with the previously $\mathrm{KG}$ determined Kulite TNT equivalency. Except for the wide dispersion in close range, there is a general agreement between the different series of values: TNT equivalent globally increases from 0.7 to 1.5 between 2 and $7 \mathrm{~m} / \mathrm{kg}^{1 / 3}$.
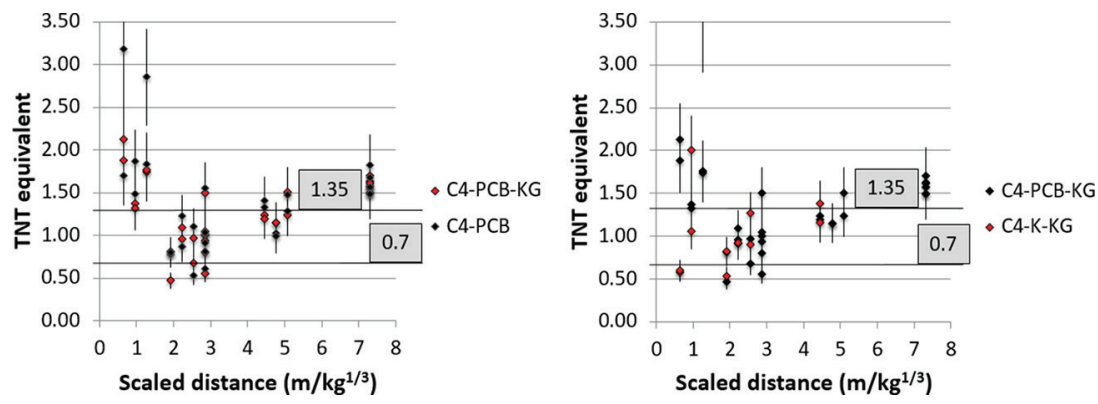

Figure 16: Influence of KG method on PCB sensors (left) and sensor type comparison (right) for C4 TNT equivalency versus scaled distance. 

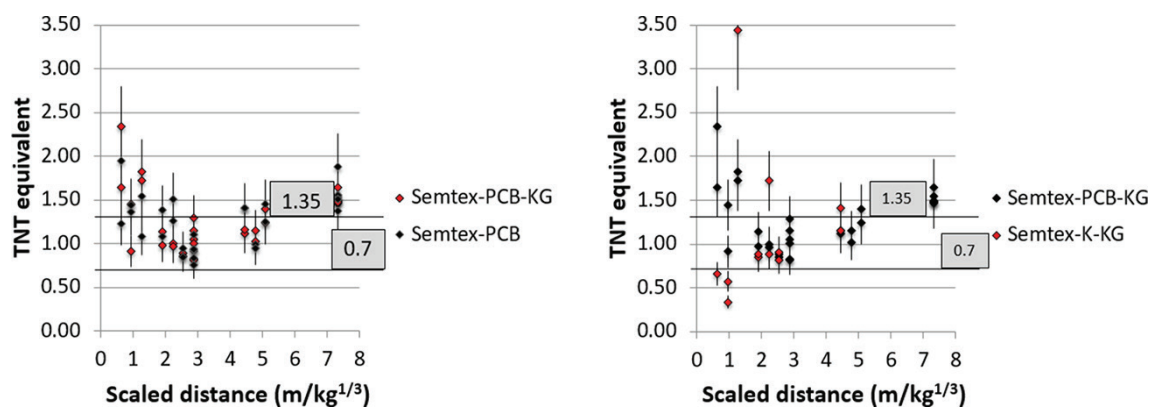

Figure 17: Influence of KG method on PCB sensors (left) and sensor type comparison (right) for Semtex TNT equivalency versus scaled distance.

Finally, all PCB pressure signals acquired for Semtex charges were processed using the KG methodology. Corresponding TNT equivalency in overpressure versus scaled distance is presented on Fig. 17, in comparison with the directly determined PCB TNT equivalency. Post-processing has no significant impact on the results dispersion. TNT equivalency globally decreases from 2 in close range down to approximately 0.7 at $3 \mathrm{~m} / \mathrm{kg}^{1 / 3}$, before increasing to 1.5 at $7 \mathrm{~m} / \mathrm{kg}^{1 / 3}$. KG calculated TNT equivalency in PCB overpressure versus scaled distance for Semtex tests is presented on Fig. 17, in comparison with the previously KG determined Kulite TNT equivalency. Except for the wide dispersion in close range, there is a general agreement between the different series of values: TNT equivalent globally increases from 1 to 1.5 between 3 and $7 \mathrm{~m} / \mathrm{kg}^{1 / 3}$.

\section{HIGH SPEED VISUALIZATION}

Several ISL blast propagations were recorded at 12000 i/s using a high-speed Phantom V310 camera equipped with a $135 \mathrm{~mm}$ f 2 lens. A white wooden board was placed behind the charge to enhance the image contrast (cf. Fig. 1). Vertical black stripes were painted every $20 \mathrm{~mm}$ to improve the detection of the shock propagation [12]. The resulting field of view covers $2.5 \mathrm{~m}$ x $0.63 \mathrm{~m}$ (1024 x 256 pixels). Figure 18 shows an example of image recorded for the TNT (2142) and Hexomax ${ }^{\circledR}$ (2141) at 1.3 ms after charge ignition, corresponding to an approximate $1.6 \mathrm{~m}$ propagation distance at ISL scale. The vertical stripes magnify the density gradient generated by the presence of shockwaves. Background Oriented Schlieren (BOS) was chosen to enhance the recorded high-speed images. The main principle of BOS is to visualize the variation of refractive index of air. Different image processing methods are described by Gregoire [13]. The technique applied for this study consists in subtracting the previous image from the current one (all images having been previously grey-scaled). Processed images are presented on Fig. 18 below the original images. BOS reveals that for both tests, the leading front is complex and composed of a main shock and several conical shocks usually generated by the flight of solid pieces of material (part of detonator, small stone, etc.). For the TNT test, the contact volume with the ground [12] seems less complex than for Hexomax ${ }^{\circledR}$.

The conical shocks intensity seems lower in the case of TNT. This observation is supported by the pressure profiles recorded at $1.6 \mathrm{~m}$ at ISL scale (Fig. 19): amplitude of multiple peaks behind the leading shock seems lower for TNT than for Hexomax ${ }^{\circledR}$. The interaction between the shock front and the sensor position located on the ground surface is difficult to analyse on such high-speed images for different reasons: the 3D nature of the multiple shocks, the lack of luminosity, limited image resolution and acquisition frequency. 


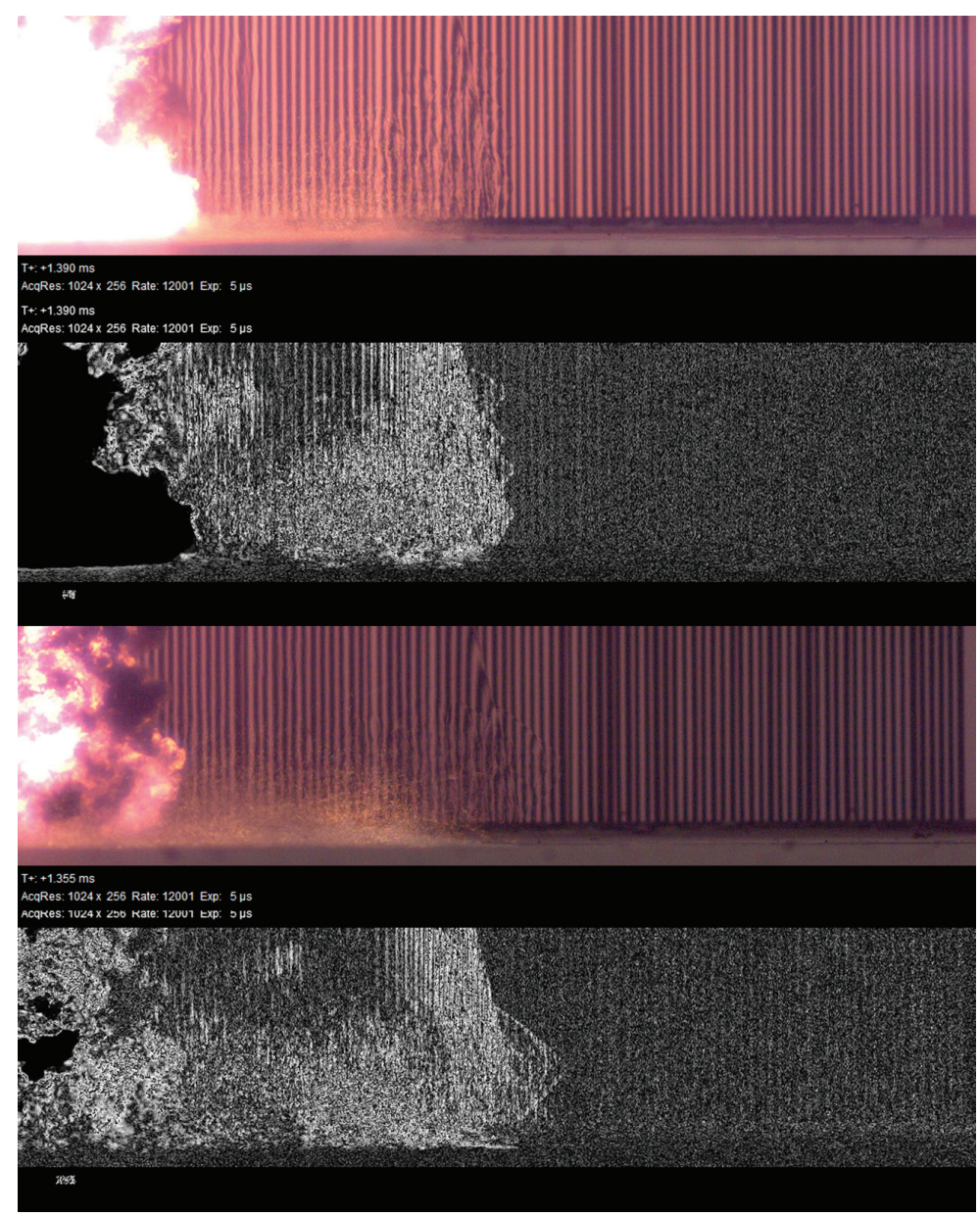

Figure 18: Original and BOS images for the TNT (top) and Hexomax ${ }^{\circledR}$ (bottom) tests at 1.3 $\mathrm{ms}$ (orange line indicating the $1.6 \mathrm{~m}$ sensor position at ISL scale distance).

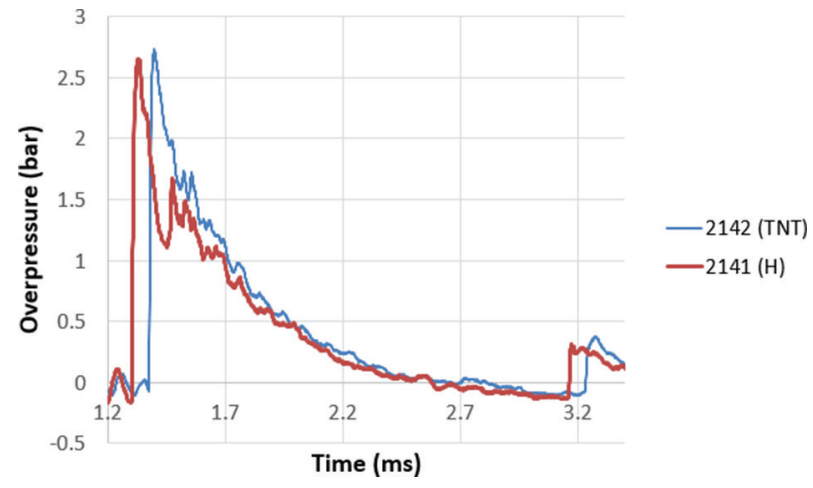

Figure 19: Pressure evolution at $1.6 \mathrm{~m}$ at ISL scale for the Hexomax® and TNT tests. 


\section{CONCLUSIONS}

Free-field hemispherical blast waves were generated by different types of high explosives at two different scales: IRSN test table and twice up-scaled ISL blast pad. Hexomax ${ }^{\circledR}$ charges were studied at the two different scales: $41.6 \mathrm{~g}$ at IRSN and $333 \mathrm{~g}$ at ISL. Concerning peak overpressures, best overall repeatability was observed for IRSN test series. C-4 and Semtex plastic explosives blast characteristics were also studied at ISL scale. ISL produced $400 \mathrm{~g}$ TNT charge to provide a direct reference for equivalency determination. High-speed imaging highlighted some details of the interaction between the blast wave and the ground surface at ISL: leading conical shocks generated by projected material interfere with the pressure measurement, in addition to all other phenomena present on the contact surface.

Two types of pressure gauges were used to measure the time evolution at different distances from the charge centre: piezo-resistive Kulite and piezo-electric PCB and Kistler (only for reproducibility in this part of the study) sensors. The differences in response time between the two technologies led to slightly different TNT equivalencies measured for the three plastic explosives. For Kulite sensors, the general trend for all plastic explosive was a progressive increase from values below 1 in close range (scaled distance below $1 \mathrm{~m} / \mathrm{kg}^{1 / 3}$ ) to values around 1.3 at $5 \mathrm{~m} / \mathrm{kg}^{1 / 3}$. For PCB sensors, as the scaled distance increases, we observed a decrease from high non-physical values down to less than 1 at $3 \mathrm{~m} / \mathrm{kg}^{1 / 3}$, up to 1.5 at $7 \mathrm{~m} / \mathrm{kg}^{1 / 3}$. These extreme values for PCB sensors may be due to sensor oversensitivity in close range and a non-adapted TNT correlation.

Based on Kinney \& Graham methodology [8], we proposed a processing technique of overpressure time history recorded during our experimental campaigns. A new set of peak overpressure values were calculated for TNT and all other plastic explosives, leading to a different TNT equivalency correlation and consequent reprocessed TNT equivalents. These new results represent a more physical approach to TNT equivalency than the direct peak overpressure determination. Comparison with directly determined TNT equivalents showed no significant extra dispersion for both Kulite and PCB sensors. Results could however be improved by refining the criteria for KG post-processing of the pressure signals depending on the sensor type. Except in close range, results obtained with both types of sensors proved to be in good agreement, with a global increase of TNT equivalency on the range of scaled distances.

Hexomax ${ }^{\circledR}$ scalability between the two configurations proved to be good in first peak overpressure value. It consequently represents a good plastic explosive candidate for pressure effects assessment in this range of scaled distances $\left(0.5\right.$ to $\left.5 \mathrm{~m} / \mathrm{kg}^{1 / 3}\right)$ at the two considered scales, with some additional work to be conducted to completely validate the close range. Influence of charge mass should be examined in a future study, as we observed that TNT equivalency in close range seemed slightly lower for IRSN smaller charges.

For all plastic explosive compositions, TNT equivalent in close range appeared to be lower than the manufacturer specification. Blast effects assessment on target in close range from similar charges should consequently be considered with care $[14,15]$, in order not to underestimate mechanical effects at full scale.

Finally, the experimental conditions surrounding the TNT equivalencies determined in this study should be stressed: peak overpressure for plastic explosives were recorded using the same pressure sensors and the same scale (except for Hexomax ${ }^{\circledR}$ ) used for the TNT reference correlation determination. Application of this methodology to other scales and types of sensors, using the present TNT correlations, should be examined to provide additional guidelines. 


\section{REFERENCES}

[1] Cheval, K., Loiseau, O. \& Vala, V., Laboratory scale tests for the assessment of solid explosive blast effects. Part I: Free-field test campaign. Journal of Loss Prevention in the Process Industries, 23(5), pp. 613-621, 2010. https://doi.org/10.1016/j.jlp.2010.05.001

[2] Cheval, K., Loiseau O. \& Vala V., Laboratory scale tests for the assessment of solid explosive blast effects, Part II: Reflected blast series of tests. Journal of Loss Prevention in the Process Industries, 25(3), pp. 436-442, 2012. https://doi.org/10.1016/j. jlp.2011.11.008

[3] Trélat, S., Impact de fortes explosions sur les bâtiments représentatifs d'une installation industrielle, PhD Thesis, Université d'Orléans, 2006.

[4] Sochet, I., Blast Effects, Springer, 2018.

[5] Kingery, C.N. \& Pannill B.F., Peak Overpressure vs Scaled Distance for TNT Surface Bursts (Hemispherical Charges), Ballistic Research Laboratories Memorandum Report No. 1518, 1964.

[6] Gibbs, T.R. \& Popolato, A., LASL Explosive Property Data, Los Alamos Series on Dynamic Material Properties, Berkeley, CA, University of California Press, 1980.

[7] Cooper, P.W., Explosives Engineering, New York : Wiley-VCH, 1996.

[8] Kinney, G. \& Graham, K., Explosive Shocks in Air, 2nd ed., Springer Verlag, 1985.

[9] Baker, W.E., Cox, P.A., Westine, P.S., Kulesz, J.J. \& Strehlow, R.A., Explosion hazards and evaluation. Fundamental Studies in Engineering, Elsevier, New York, Elsevier, 1983.

[10] Gitterman, Y., Secondary shock features for large surface explosions: results from the Sayarim military range, Israel and other experiments. Shock Waves, 24(3), pp. 267-282, 2014. https://doi.org/10.1007/s00193-013-0487-y

[11] Ethridge, N.H., A Procedure for Reading and Smoothing Pressure- Time Data From H. E. and Nuclear Explosions, Ballistic Research Laboratories Memorandum Report No. 1691, 1965.

[12] Needham, C.E., Blast Waves, Springer, 2010.

[13] Grégoire, Y., Etude expérimentale et numérique de la dispersion explosive et de la combustion de particules métalliques. PhD Thesis, ENSMA, Université de Poitiers, 2009.

[14] Locking, P.M., The Trouble with TNT Equivalent, 26th International Symposium on Ballistics, Miami, USA, 2011.

[15] Collet, C., Baker E.L. \& Van der Voort M., TNT and Blast Equivalency Characterization, Europyro- 44th International Pyrotechnics Society Seminar, Tours, France, 2019. 